\title{
Proton magnetic spectroscopy agreed better with magnetic resonance image to lateralization of epileptogenic zone than with surface electroencephalography
}

\author{
Espectroscopia de prótons de hidrogênio na \\ investigação ambulatorial das epilepsias extra-temporais \\ Ricardo André Amorim Leite1, Maria Concépcion Garcia Otaduy², Gilson Edmar Gonçalves e Silva³, \\ Maria Lúcia Brito Ferreira ${ }^{1}$, Maria de Fátima Vasco Aragão ${ }^{4}$
}

\begin{abstract}
Objective: To analyze the agreement rate of proton magnetic spectroscopy with magnetic resonance image (MRI) and surface electroencephalography (EEG) in extratemporal neocortical epilepsies. Methods: A cross-sectional study, type series of cases included 33 patients, age range 13-59 years old, of both gender, presenting structural alteration identified by MRI (75.8\%) or by neurophysiologic techniques (72.7\%). The variables were alterations of $\mathrm{N}$-acetyl-aspartate/choline, $\mathrm{N}$-acetyl-aspartate/creatine, choline/creatine, and $\mathrm{N}$-acetyl-aspartate/choline+creatine coefficient of asymmetry. Results: Agreement rates of lateralization by coefficient of asymmetry of NAA/Cho, NAA/Cr, Co/Cr, and NAA/Cho+Cr with MRI, independent of alteration of surface EEG, were equal to 93.3, 57.9, 15.4, and 93.3\%, respectively, modifying to 100, 33.3, 0, and 100\%, in 16 patients, with lateralization agreement of MRI and surface EEG. Conclusion: Proton magnetic spectroscopy agreed better with MRI to lateralization of epileptogenic zone than with surface EEG.
\end{abstract}

Key words: extratemporal neocortical epilepsy, magnetic resonance spectroscopy, EEG.

\section{RESUMO}

Objetivo: Analisar a taxa de concordância da espectroscopia de prótons de hidrogênio com imagem de ressonância magnética (IRM) e o eletrencefalograma (EEG) de superfície nas epilepsias neocorticais extratemporais. Métodos: Estudo transversal, série de casos, incluiu 33 pacientes, com idade de 13 a 59 anos, de ambos os gêneros, apresentando alteração estrutural à IRM (75,8\%) ou neurofisiológica à (72,7\%). As variáveis estudadas foram as alterações dos coeficientes de assimetria de N-acetil-aspartato/colina, N-acetil-aspartato/creatina, Colina/Creatina e N-acetil-aspartato/colina+creatina. Resultados: As taxas de concordância de lateralização dos coeficientes de assimetria de NAA/Co, NAA/Cr, Co/Cr e NAA/Co+Cr com a IRM, independentemente de alterações do EGG de superfície, passaram de 93,3, 57,9, 15,4, 93,3\%, respectivamente, para 100,33,3, zero, 100\%, em 16 pacientes, mostrando concordância de lateralização entre IRM e EEG de superfície. Conclusão: A espectroscopia de prótons de hidrogênio concordou melhor com a lateralização da zona epileptogênica pela IRM do que com o EEG de superfície.

Palavras-Chave: epilepsias neocorticais extratemporais, espectroscopia por ressonância magnética, EEG.

Amongst the epilepsies, the focal, symptomatic or probably symptomatic, and neocortical necessarily require the localization and the lateralization of epileptogenic zone to establish diagnose and to institute clinical or surgical adequate treatment. Due to the characteristics of the extratemporal epilepsies, which make them more complex than the temporal epilepsies, they require more sensible and specific diagnostic methods. These methods include electroencephalography (EEG), magnetic resonance image (MRI), and, more recently, the hydrogen proton spectroscopy.

\footnotetext{
'Epilepsy and Neurophysiology Center of the Neurology Department, Hospital da Restauração, Recife PE, Brazil;

${ }^{2}$ Neuroradiology Service of Universidade de São Paulo, São Paulo SP, Brazil;

${ }^{3}$ Neurology Department of Universidade Federal de Pernambuco, Recife PE, Brazil;

${ }^{4}$ Neuroradiology Department of Multimagem, Recife PE, Brazil.

Correspondence: Ricardo André Amorim Leite; Rua Dr. Sabino Pinho 210 /apto. 05; 50610-380 Recife PE - Brasil; E-mail: richards_250975@yahoo.com.br Conflict of interest: There is no conflict of interest to declare.

Received 2 September 2012; Received in final form 23 April 2013; Accepted 30 April 2013.
} 
The surface EEG presents low sensibility for extratemporal epilepsies, when compared with identical application for temporal epilepsies, although it is considered an essential method for diagnose, characterization, and localization of these epilepsies ${ }^{1}$, independent of epileptogenic zone.

The MRI is recognized as the best noninvasive method to the structural evaluation of brain ${ }^{2,3}$, and also the method of election for epilepsies refractive to drug treatment with surgical indication, because MRI has high sensibility and specificity for lesions like tumors, neuronal migration errors (specially dysplasia), hypoxic ischemic injuries, infections, metabolic errors, trauma, neurocutaneous diseases, vascular malformations, gliosis, etc. ${ }^{4-6}$.

The advent of surgery for the treatment of epilepsies demanded the investigation of new methods for therapeutic planning. Functional magnetic resonance ${ }^{4}$, positron emission tomography and single photon emission tomography ${ }^{5}$, diffusion tensor resonance, and tractography of fibers were developed ${ }^{7-9}$. Nevertheless, there is still a lacuna of diagnose and therapeutical follow-up of patients with neocortical extratemporal epilepsies, which makes the possibility of cure for these seizures difficult.

The magnetic resonance spectroscopy (MRS) and the MRI use the same physical principles, differing only in the way by which these data are processed and presented. MRS has graphic images, instead of anatomical images, where some brain metabolites, invisible on MRI, are identified ${ }^{10}$. The hydrogen proton spectroscopy is more used, due to the abundance of this atom in the organism, and also due to the fact that it provides a more intense signal ${ }^{11}$, which permits the identification of the metabolites N-acetyl-aspartate (NAA), choline (Cho), creatine $(\mathrm{Cr})$, amongst others ${ }^{10,12}$.

For epileptic individuals, NAA may be reduced due to diffusion, neuronal lesion, or an increase of the energy consumption wasted on electrical discharges ${ }^{13,14}$.

On epilepsies, the researchers have objectified to identify the relation between the metabolite alterations and the modifications on EEG, video EEG, and MRI, to establish diagnostic standards of localization and lateralization of epileptogenic zone. The studies involving normal persons concluded that brain asymmetries right-left type are not found, and the distribution patterns of NAA, Cho, and Cr metabolites are specific to each brain region ${ }^{13}$.

These findings pointed out the possibility that spectroscopy, in the future, may constitute an important exam within the arsenal of therapeutic, diagnose, and follow-up planning, and this has been the motivation for this research, which aims to analyze the efficacy of hydrogen proton magnetic spectroscopy for ambulatory evaluation of focal extratemporal epilepsies.

\section{METHODS}

The study has been a cross-sectional, type series of cases. The patient group consisted of persons, age range 13-59 years old, of both gender, with focal neocortical extratemporal epilepsy, diagnosed at the outpatient department from March to October 2006, presenting a unilateral lesion diagnosed by MRI or a lateralized interictal abnormality identified by surface EEG. The exclusion criteria were the presence of concomitant diagnose of other types of epilepsy, constant absence to ambulatory follow-up consultations, presence of diffuse lesion identified by MRI, undefined lateralization identified by EEG, and the refusal of the patient or his responsible to participate in the research.

Three centers participated in this research: The Epilepsy Ambulatory of Hospital da Restauração (Recife, Pernambuco, Brazil) where the patient group were diagnosed, followed, and submitted to EEG; the Multimagem Radiology Service (Recife, Pernambuco, Brazil), where MRI and $1 \mathrm{H}^{+} \mathrm{MRS}$ were performed; and the Radiology Service of Clinical Hospital at Universidade de São Paulo (São Paulo, Brazil), where data were processed and analyzed.

The sample constituted of 33 patients, with mean age equal to $25.18 \pm 11.39$ years, varying from 13 to 59 years old, with a predominance of male gender $(63.6 \%)$, less than four years of instruction (60.6\%) and occupation as student (45.5\%). For $33.3 \%$ of patients, epileptic seizures were focal secondary generalized, amongst which $75.8 \%$ were symptomatic. The nosologies of epilepsy more often were pre- or perinatal hypoxia (27.4\%), head trauma (15.2\%), and postsurgical status $(9.1 \%)$.

The variables were alterations in brain metabolite ratio $\mathrm{NAA} / \mathrm{Cho}, \mathrm{NAA} / \mathrm{Cr}$, and $\mathrm{NAA} / \mathrm{Cho}+\mathrm{Cr}$, evaluated by pike metabolite area of $1 \mathrm{H}^{+} \mathrm{MRS}$ with long ET of $135 \mathrm{~ms}$ and multivoxel simultaneous acquisition; morphological alterations diagnosed by MRI (normal and with lesion); and neurophysiological alterations identified by EEG (normal and with interictal activity).

After a neurological anamnesis, the authors obtained data concerning patient's identification and submitted them to MRI with a 1.5 Tesla equipment, model Signa Infinity (General Electric Health Care, Milwaukee, WI, USA). The T1 and $\mathrm{T} 2$ image sequences of brain magnetic resonance were obtained, before contrast, within axial and coronal planes, with the patient in dorsal decubit at the exam table.

The parameters for spin-echo axial image acquisition on $\mathrm{T} 1$ were repetition time of $500 \mathrm{~ms}$, echo time $14 \mathrm{~ms}$, slice thickness $5 \mathrm{~mm}$, slice interval $2.5 \mathrm{~mm}$, matrix 256×192 and number of excitations (NEX) equal to 2. Axial images on T2, with fast spin-echo technique, were obtained with $\mathrm{RT}=4000 \mathrm{~ms}$, $\mathrm{ET}=100 \mathrm{~ms}, \mathrm{ST}=5 \mathrm{~mm}$ and $\mathrm{SI}=2.5 \mathrm{~mm}$, matrix $=320 \times 224$ and $\mathrm{NEX}=2$. The spoiled gradient-recalled echo (SPGR) volume technique has also been used with $\mathrm{RT}=25 \mathrm{~ms}, \mathrm{ET}=4.2$, FOV $=24 \mathrm{~cm}$, slice $=0.5 \times 0.7$, matrix $=192 \times 192$, and NEX $=1$.

To perform multivoxel $1 \mathrm{H}^{+} \mathrm{MRS}$, a $\mathrm{T} 2$ axial image of brain was the reference. Within this image, one has identified voxel localization, guided by EEG or MRI, and selected the region for $1 \mathrm{H}^{+} \mathrm{MRS}$, which has been compared with the contralateral one. 
Multivoxel $1 \mathrm{H}^{+} \mathrm{MRS}$ was performed bypoint-resolved spectroscopy technique (PRESS), with RT=1500 ms, ET=135 ms, voxel slice $=10 \mathrm{~mm}$, vision field $=24 \mathrm{~cm}$, phase codification $=16 \times 16, \mathrm{NEX}=1$, and anterior posterior frequency direction.

After multivoxel $1 \mathrm{H}^{+} \mathrm{MRS}$ acquisition, one has injected contrast with a volume correspondent to gadopentetate dimeglutamine (Magnograf ${ }^{\circledR}$ ) $0.2 \mathrm{~mL}$ per kg of the patient's body weight, intravenously, within approximately $30 \mathrm{~s}$. The acquisition of postcontrast T1 images was obtained in sagittal, coronal, and axial planes and concluded the first phase of multivoxel $1 \mathrm{H}^{+} \mathrm{MRS}$.

The second phase, also named data postprocessing, aimed to transform raw data into graphics. It has been performed at a work station Sun 60-Ultrasparc ${ }^{\circledR}$, at the Radiology Department of Clinics Hospital of Universidade de São Paulo, São Paulo, Brazil. Raw data were transferred from diskettes and compact disks to the work station, where they were converted with SA/GE ${ }^{\circledR}$ (General Electric Health Care, Milwaukee, WI, USA) software.

The chosen voxel was localized at the white matter of the analyzed brain lobe, next to the lesion when localized by MRI, or even next to the brain cortex, when analyzed by EEG (Figure). In accordance to these criteria, to avoid voxels on peripheral areas that could be noisy or present diminished

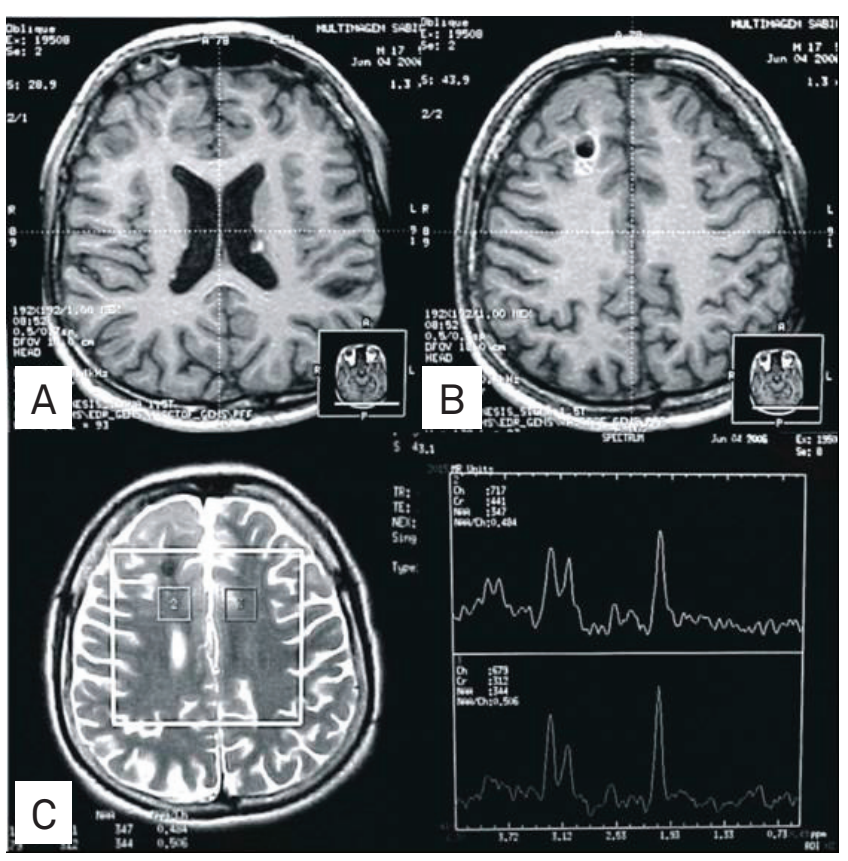

Figure. Patient 20 - Complex tuberous sclerosis and epileptogenic zone lateralized to the right brain hemisphere by magnetic resonance image and $1 \mathrm{H}^{+}$magnetic resonance spectroscopy. (A) Axial $T_{1}$ image, with hyperintense subependimary nodules; (B) Axial $T_{1}$ image, showing calcified cortical and subcortical tuber in right frontal lobe; (C) Axial $\mathrm{T}_{2}$ image used to place voxel in frontal region. Spectroscopic graphic demonstrates a significant reduction in NAA/Cho, $\mathrm{NAA} / \mathrm{Cr}$, and $\mathrm{NAA} / \mathrm{Cho}+\mathrm{Cr}$ ratios on the right frontal lesion. signal, two or three integers of pick areas of each brain metabolite (NAA, Cho, and $\mathrm{Cr}$ ) were registered on a special protocol.

In the third phase, the analysis of multivoxel $1 \mathrm{H}^{+} \mathrm{MRS}$ consisted in the determination of metabolite means, to calculate metabolite indexes by NAA/Cr, NAA/Cho, NAA/Cho+Cr, and $\mathrm{Cho} / \mathrm{Cr}$ ratios, followed by the determination of the respective coefficients of asymmetry $\left(C_{a}\right)$, according to formula ${ }^{15}$ :

$$
\mathrm{C}_{\mathrm{a}}=2 \mathrm{x}\left(\frac{\left({ }^{\mathrm{x}} \mathrm{R}_{\text {left }}-{ }^{\mathrm{x}} \mathrm{R}_{\text {right }}\right)}{\left({ }^{\mathrm{x}} \mathrm{R}_{\text {left }}+{ }^{\mathrm{x}} \mathrm{R}_{\text {right }}\right)}\right)
$$

where:

$\mathrm{x} \rightarrow$ analyzed metabolite ratio

$R_{\text {left }} \rightarrow$ value of metabolite ratio in the left brain hemisphere

$R_{\text {right }} \rightarrow$ value of metabolite ratio in the right brain hemisphere

The coefficients of asymmetry of patients were compared with those of the control group, by ANOVA test, followed by $t$-test for paired samples at a significance level of 0.05 .

Surface EEG were performed at the Electroencephalography Department of Epilepsy and Neurophysiology Center, by $10-20$ system, on scalp with 20 electrodes, of EMSA ${ }^{\circledR}$ equipment, brainwave model, using a 20-min standard examination, and analysis with $15 \mathrm{~mm} / \mathrm{s}$ speed and $100 \mu \mathrm{V}$ amplitude. Activation methods were ocular opening and closure, photo stimulation, and hyperpnoea.

Data organization was performed within EPI-INFO software version 6.04d and statistical analysis with Statistical Package for Social Sciences, version 13.0.

To analyze the concordance of epileptic zone lateralization between complementary methods used in this research, we admitted that individuals without neurological diseases have no significant differences between metabolite concentration and its ratios in the right brain hemisphere compared with the left, for voxels within correlated areas, as well as there is a reduction of metabolite concentration and ratios in the brain hemisphere with epileptogenic foci.

Due to these assumptions and assuming the 95\% confidence interval of control group as reference, a coefficient of asymmetry minor than the lower limit has indicated right lateralization, and, when major than the upper limit, left lateralization.

This research has been approved by the Ethics Committee on Research of Hospital da Restauração, under registration CAAE $n^{\circ}$. 0086.0.102.840.05. All patients agreed to participate in this study by signing an Informed Free Consent Term after receiving explication about the objectives of the research and elucidation of possible doubts.

\section{RESULTS}

Table 1 expresses case to case, type, and anatomical lesion localization by MRI; interictal alteration and its projection in 
Table 1. Distribution of MRI and electroencephalography results and interhemispheric coefficients of asymmetry of 33 patients with neocortical extratemporal epilepsy - Recife, March/October 2006.

\begin{tabular}{|c|c|c|c|c|c|c|c|c|}
\hline \multirow[b]{2}{*}{ Reg } & \multicolumn{2}{|c|}{ MRI } & \multicolumn{2}{|l|}{ EEG } & \multirow[b]{2}{*}{$\begin{array}{l}\mathrm{C}_{\mathrm{a}} \mathrm{NAA} / \\
\text { Cho* }\end{array}$} & \multirow[b]{2}{*}{$\begin{array}{l}\mathrm{C}_{\mathrm{a}} \mathrm{NAA} / \\
\mathrm{Cr}^{*}\end{array}$} & \multirow{2}{*}{$\begin{array}{l}\mathrm{C}_{\mathrm{a}} \mathrm{NAA} / \\
\text { Cho+Cr* }\end{array}$} & \multirow[b]{2}{*}{$\begin{array}{l}\mathrm{C}_{\mathrm{a}} \mathrm{Cho/} \\
\mathrm{Cr}^{*}\end{array}$} \\
\hline & Result & $\begin{array}{l}\text { Lesion localiza- } \\
\text { tion }\end{array}$ & Result & Localization & & & & \\
\hline 1 & $\begin{array}{l}\text { CNS primary } \\
\text { neoplasia }\end{array}$ & Frontal R & Normal & & 0.2215 & 0.1034 & -0.1188 & 0.1648 \\
\hline 2 & Gliosis & Frontal L & Normal & & -0.0080 & -0.2875 & -0.2796 & -0.1383 \\
\hline 3 & Normal & & $\begin{array}{l}\text { Spike wave and polispike } \\
\text { wave }\end{array}$ & Frontal L & -0.3257 & -0.2258 & 0.1018 & -0.2651 \\
\hline 4 & Gliosis & Parietoccipital L & Sharp wave and slow wave & Parietoccipital L & -0.1230 & 0.3895 & 0.5064 & 0.1118 \\
\hline 5 & Gliosis & $\begin{array}{l}\text { Frontoparietoc- } \\
\text { cipital R }\end{array}$ & Teta regional rhythm & Frontoparietal R & 0.0270 & -0.2912 & -0.3176 & -0.1287 \\
\hline 6 & Gliosis & Frontoccipital L & Normal & & 0.0182 & -0.2157 & -0.2337 & -0.1034 \\
\hline 7 & Gliosis & Parietoccipital L & Spike and spike wave & Parietoccipital L & -0.1861 & 0.2478 & 0.4290 & 0.0133 \\
\hline 8 & Gliosis & Frontal R & Spike wave & Frontal R & 0.0133 & -0.2894 & -0.3024 & -0.0696 \\
\hline 9 & Normal & & $\begin{array}{l}\text { Spike wave, sharp wave, } \\
\text { and slow wave }\end{array}$ & Frontal R & 0.1514 & 0.1991 & 0.0481 & 0.1716 \\
\hline 10 & Dysplasia & Frontal L & Normal & & -0.0440 & -0.2878 & -0.2445 & -0.1480 \\
\hline 11 & Gliosis & Frontal L & $\begin{array}{l}\text { Spike wave, sharp wave, } \\
\text { and slow wave }\end{array}$ & Frontal R & -0.0877 & -0.2394 & -0.1525 & -0.1724 \\
\hline 12 & Normal & & $\begin{array}{l}\text { Spike wave, sharp wave, } \\
\text { and slow wave }\end{array}$ & Parietoccipital L & -0.0674 & 0.1447 & 0.2116 & 0.0395 \\
\hline 13 & Gliosis & Frontal R & Spike and sharp wave & Frontal R & -0.0126 & -0.1288 & -0.1163 & -0.0695 \\
\hline 14 & Polymicrogyria & Frontoccipital L & Normal & & 0.2481 & -0.0176 & -0.2654 & 0.1255 \\
\hline 15 & Normal & & Sharp wave & Frontal R & 0.1666 & -0.4565 & -0.6115 & -0.2128 \\
\hline 16 & Gliosis & Frontal L & Spike and spike wave & Frontal L & -0.3081 & 0.0016 & 0.3097 & -0.1296 \\
\hline 17 & Dysplasia & Parietoccipital L & Sharp wave and slow wave & Parietal L & -0.4363 & -0.4612 & -0.0263 & -0.4482 \\
\hline 18 & Normal & & $\begin{array}{l}\text { Spike wave, sharp wave, } \\
\text { and slow wave }\end{array}$ & Frontal R & -0.1583 & -0.3734 & -0.2183 & -0.2684 \\
\hline 19 & Gliosis & Frontoparietal L & Spike wave & Frontoparietal L & -0.4201 & 0.3129 & 0.7096 & -0.1079 \\
\hline 20 & Cortical tuber & Frontal R & Normal & & 0.2672 & 0.1787 & -0.0896 & 0.2206 \\
\hline 21 & Neurocisticercosis & Frontal R & Normal & & -0.0679 & 0.1756 & 0.2427 & 0.0476 \\
\hline 22 & Normal & & $\begin{array}{l}\text { Spike wave, sharp wave, } \\
\text { and slow wave }\end{array}$ & Frontoparietal L & 0.1424 & -0.0714 & -0.2133 & 0.0490 \\
\hline 23 & $\begin{array}{l}\text { CNS venous malfor- } \\
\text { mation }\end{array}$ & Frontal R & Sharp wave and slow wave & Frontal L & 0.2076 & 0.0417 & -0.1662 & 0.1288 \\
\hline 24 & Normal & & Sharp wave and slow wave & Frontal R & -0.5495 & -0.6029 & -0.0582 & -0.5730 \\
\hline 25 & Normal & & Sharp wave & Frontal R & 0.0777 & -0.0373 & -0.1149 & 0.0239 \\
\hline 26 & Gliosis & Frontal L & Low amplitude & Frontal L & -0.0975 & -0.3437 & -0.2483 & -0.2460 \\
\hline 27 & Gliosis & Frontoparietal R & Sharp wave and slow wave & Frontoparietal R & 0.0978 & -0.1858 & -0.2824 & -0.0480 \\
\hline 28 & Gliosis & Parietal R & Teta regional rhythm & Parietoccipital R & 0.6415 & -0.2930 & -0.8925 & 0.1212 \\
\hline 29 & Gliosis & $\begin{array}{l}\text { Frontoparietoc- } \\
\text { cipital R }\end{array}$ & Delta regional rhythm & Frontal R & 0.8909 & 0.2328 & -0.6941 & 0.5807 \\
\hline 30 & Gliosis & $\begin{array}{l}\text { Frontoparietoc- } \\
\text { cipital L }\end{array}$ & Spike wave & Frontal L & -0.0824 & 0.1490 & 0.2307 & 0.0112 \\
\hline 31 & Neurocisticercosis & Frontal L & Normal & & 0.1067 & 0.0242 & -0.0826 & 0.0637 \\
\hline 32 & Gliosis & Parietal L & $\begin{array}{l}\text { Spike wave and sharp } \\
\text { wave }\end{array}$ & Frontoparietal L & -0.2118 & -0.3210 & -0.1111 & -0.2683 \\
\hline 33 & Gliosis & Frontal L & Normal & & -0.4238 & -0.2245 & 0.2041 & -0.3158 \\
\hline
\end{tabular}

Negrite values were minor or major than the respective 95\% confidence interval limits. MRI: magnetic resonance image; L: left; R: right; CNS: central nervous system.

brain cortex diagnosed by surface EEG; as well as the interhemisphere coefficients of asymmetry.

Comparing the coefficients of asymmetry of NAA/Cho, $\mathrm{NAA} / \mathrm{Cr}, \mathrm{NAA} / \mathrm{Cho}+\mathrm{Cr}$, and $\mathrm{Cho} / \mathrm{Cr}$ ratios of 33 patients with the limits of a $95 \%$ confidence interval of control group, one has identified that 29 (87.9\%) patients presented significant differences: 18 (54.5\%) for NAA/Cho, 25 (75.7\%) for NAA/Cr, $20(60.6 \%)$ for NAA/Cho+Cr, and $16(48.5 \%)$ for Cho/Cr.

Considering only 25 patients who presented lateralized lesion by MRI, 23 (92\%) had a significant coefficient of 
asymmetry compared with the reference group, 15 (60.0\%) with $\mathrm{NAA} / \mathrm{Cho}$ or $\mathrm{NAA} / \mathrm{Cho}+\mathrm{Cr}$ ratios, $19(76 \%)$ with NAA/Cr ratios, and 13 (52\%) with Cho/Cr ratios.

Lateralization concordance rates between MRI and $1 \mathrm{H}^{+} \mathrm{MRS}$ were 93.3, 57.9, 93.3, and $15.4 \%$, respectively, evaluated by NAA/Cho, NAA/Cr, NAA/Cho+Cr, and Cho/Cr ratios (Table 2).

With respect to 24 patients who presented lateralization by interictal activity by EEG, 21 (87.5\%) showed a significant coefficient of asymmetry when compared with the reference group, 14 (58.3\%) with NAA/Cho and NAA/Cho+Cr ratios, 19 (79.2\%) with NAA/Cr ratios, and 13 (54.2\%) with Cho/Cr ratios.

Lateralization concordance rates between EEG and $1 \mathrm{H}^{+} \mathrm{MRS}$ were equal to $78.6,31.6$, and $57.2 \%$, related to $\mathrm{NAA} / \mathrm{Cho}, \mathrm{NAA} / \mathrm{Cr}$, and $\mathrm{NAA} / \mathrm{Cho}+\mathrm{Cr}$ ratios, respectively. There was no concordance between EEG and $\mathrm{Cho} / \mathrm{Cr}$ ratios (Table 2).

Concerning 16 patients who presented lateralization of interictal activity identified by EEG and an anatomical lesion by MRI, 15 (93.8\%) showed a significant coefficient of asymmetry when compared with the reference group, 11 (68.8\%) with NAA/Cho ratios, 13 (81.3\%) with NAA/Cr ratios, 9 (56.3\%) with NAA/Cho+Cr ratios, and 10 (62.5\%) with Cho/Cr ratios. Lateralization concordance rates between EEG and $1 \mathrm{H}^{+} \mathrm{MRS}$ were equal to $91,30.8$, and $66.7 \%$, when evaluated by NAA/Cho, NAA/Cr, and NAA/Cho+Cr, respectively, with no concordance to $\mathrm{Cho} / \mathrm{Cr}$ ratios, while concord- ance rates corresponding to MRI were equal to $100 \%, 38.5 \%$, and $88.9 \%$, respectively, and again with no concordance to Cho/Cr ratios (Table 2).

The comparison of epileptogenic zone lateralization, identified by the three methods, showed a concordance rate equal to $100 \%, 33.3 \%$, and $100 \%$, respectively for NAA/Cho, $\mathrm{NAA} / \mathrm{Cr}$, and $\mathrm{NAA} / \mathrm{Cho}+\mathrm{Cr}$, reaching 0 for $\mathrm{Cho} / \mathrm{Cr}$ ratios (Table 2).

Among nine patients with lesion lateralization on MRI associated with a normal EEG, eight (88.9\%) had a significant coefficient of asymmetry when compared with the reference group, three $(44.4 \%)$ with NAA/Cho ratios, six (66.7\%) with $\mathrm{NAA} / \mathrm{Cr}$ ratios, three $(33.3 \%)$ with $\mathrm{Cho} / \mathrm{Cr}$ ratios, and six $(66.7 \%)$ with $\mathrm{NAA} / \mathrm{Cho}+\mathrm{Cr}$ ratios. Lateralization concordance rates between MRI and $1 \mathrm{H}^{+} \mathrm{MRS}$, associated with normal EEG, equaled 75, 100, 66.7, and 100\%, respectively evaluated by NAA/Cho, NAA/Cr, Cho/Cr, and NAA/Cho+Cr (Table 2).

When eight patients, with interictal abnormality lateralized by EEG and associated with normal MRI, were considered, six (75\%) presented a significant difference of coefficient of asymmetry compared with the reference group, three (37.5\%) with NAA/Cho ratios, six (75\%) with NAA/Cr ratios, three $(37.5 \%)$ with Cho/Cr ratios, and five (62.5\%) with NAA/ $\mathrm{Cho}+\mathrm{Cr}$ ratios. Lateralization concordance rates between EEG and $1 \mathrm{H}^{+} \mathrm{MRS}$, associated with normal MRI, were equal to $33.3 \%$ for NAA/Cho and NAA/Cr ratios, $40 \%$ for $\mathrm{NAA} / \mathrm{Cho}+\mathrm{Cr}$ ratios, and 0 for Cho/Cr ratios (Table 2).

Table 2. Distribution of asymmetry coefficients of brain metabolite ratios evaluated by the area of spikes on spectroscopy graphic, according to lateralization determined by MRI and electroencephalography - Recife, March/October 2006.

\begin{tabular}{|c|c|c|c|c|}
\hline Evaluation of lateralization concordance & $\begin{array}{c}\mathrm{C}_{\mathrm{a}} \mathrm{NAA} / \mathrm{Cho} \\
\mathrm{n}(\%)\end{array}$ & $\begin{array}{c}\mathrm{C}_{\mathrm{a}} \mathrm{NAA} / \mathrm{Cr} \\
\mathrm{n}(\%)\end{array}$ & $\begin{array}{c}\mathrm{C}_{\mathrm{a}} \mathrm{Cho} / \mathrm{Cr} \\
\mathrm{n}(\%)\end{array}$ & $\begin{array}{c}\mathrm{C}_{\mathrm{a}} \mathrm{NAA} / \mathrm{Cho}+\mathrm{Cr} \\
\mathrm{n}(\%)\end{array}$ \\
\hline \multicolumn{5}{|l|}{ Comparison of abnormal MRI with $1 \mathrm{H}^{+} \mathrm{MRS}$} \\
\hline Patients with $1 \mathrm{H}^{+} \mathrm{MRS}$ altered & $15(60.0)$ & $19(76.0)$ & $13(52.0)$ & $15(60.0)$ \\
\hline Concordance rate with $1 \mathrm{H}^{+} \mathrm{MRS}$ & $14(93.3)$ & $11(57.9)$ & $2(15.4)$ & $14(93.3)$ \\
\hline \multicolumn{5}{|l|}{ Comparison of abnormal EEG with $1 \mathrm{H}^{+} \mathrm{MRS}$} \\
\hline Patients with $1 \mathrm{H}^{+} \mathrm{MRS}$ altered & $14(58.3)$ & $19(79.2)$ & $13(54.2)$ & $14(58.3)$ \\
\hline Concordance rate with $1 \mathrm{H}^{+} \mathrm{MRS}$ & $11(78.6)$ & $6(31.6)$ & - & $8(57.2)$ \\
\hline \multicolumn{5}{|c|}{ Comparison of abnormal MRI and abnormal EEG with $1 \mathrm{H}^{+} \mathrm{MRS}$} \\
\hline Patients with $1 \mathrm{H}^{+} \mathrm{MRS}$ altered & $11(68.8)$ & $13(81.3)$ & $10(62.5)$ & $9(56.3)$ \\
\hline Concordance rate of EEG with $1 \mathrm{H}^{+} \mathrm{MRS}^{1}$ & $10(91.0)$ & $4(30.8)$ & - & $6(66.7)$ \\
\hline Concordance rate of MRI with $1 \mathrm{H}^{+} \mathrm{MRS}^{1}$ & $11(100)$ & $5(38.5)$ & - & $8(88.9)$ \\
\hline Concordance rate of EEG and MRI with $1 \mathrm{H}^{+} \mathrm{MRS}^{2}$ & $10 / 10(100)$ & 4/12 (33.3) & - & $6 / 6(100)$ \\
\hline \multicolumn{5}{|c|}{ Comparison of abnormal MRI and normal EEG with $1 \mathrm{H}^{+} \mathrm{MRS}$} \\
\hline Patients with $1 \mathrm{H}^{+} \mathrm{MRS}$ altered & $4(44.4)$ & $6(66.7)$ & $3(33.3)$ & $6(66.7)$ \\
\hline Concordance rate of MRI with $1 \mathrm{H}^{+} \mathrm{MRS}^{1}$ & $3(75)$ & $6(100)$ & $2(66.7)$ & $6(100)$ \\
\hline \multicolumn{5}{|l|}{ Comparison of normal MRI and abnormal EEG with $1 \mathrm{H}^{+} \mathrm{MRS}$} \\
\hline Patients with $1 \mathrm{H}^{+} \mathrm{MRS}$ altered ${ }^{3}$ & $3(37.5)$ & $6(75)$ & $3(37.5)$ & $5(62.5)$ \\
\hline Concordance rate of EEG with $1 \mathrm{H}^{+} \mathrm{MRS}^{1}$ & $1(33.3)$ & $2(33.3)$ & - & $2(40)$ \\
\hline
\end{tabular}

'Percentages based on total of patients with abnormal differences of asymmetry coefficient; ${ }^{2}$ Percentages based on a total of patients with concordant lateralization between EEG and MRI; ${ }^{3}$ Percentages based on eight patients with abnormalities restricted to EEG; MRI: magnetic resonance image; MRS: magnetic resonance spectroscopy. 


\section{DISCUSSION}

The localization and lateralization of the epileptogenic zone received special attention after the advent of surgical treatment, because the determination of this zone permitted its resection, which can cure seizures, when successful, or at least can adequately control them with small doses of antiepileptic drugs ${ }^{16}$.

Among epilepsies, the neocortical present high level of diagnose difficulty due to the great number of brain intraand interhemisphere network connections, which generate diagnose doubts concerning neurophysiology, functional neuroradiology, and neuroimaging ${ }^{17}$.

These challenges motivated the research methods able to refine the localization and lateralization of epileptogenic zone, including routine EEG, long-term video-EEG, MRI, PET, SPECT, and hydrogen proton spectroscopy ${ }^{18}$.

While routine EEG investigate types and localization of electric brain abnormalities, the MRI shows encephalic structural lesions, and the MRS determines the disturbances of brain metabolites, such as NAA, Cho, and $\mathrm{Cr}^{15,19-21}$.

Based on the aspects of brain metabolism here pointed out, we tried to explain the results of the asymmetry coefficient reduction of $\mathrm{NAA} / \mathrm{Cho}, \mathrm{NAA} / \mathrm{Cr}, \mathrm{NAA} / \mathrm{Cho}+\mathrm{Cr}$, and $\mathrm{Cho} / \mathrm{Cr}$ in patients with neocortical extratemporal epilepsy.

In epilepsy, there is a reduction of neuron population derived from the physical and chemical aggression, which determines neuronal damage with reduction of NAA mitochondrial synthesis, represented by diminishing of this metabolite concentration, which is biomarker of neuron quantity and viability ${ }^{22}$.

Another possible mechanism implied in the reduction of NAA is based on the comparison of generalized and occipital epilepsies. The first ones show increase of glutamine-glutamate and GABA, while on the second ones this increase is restricted just to GABA. Identifying many interictal epileptogenic discharges, we can admit the hypothesis of a great demand of glutamine-glutamate (excitatory neurotransmitters), and as a compensatory mechanism, the increase of GABA synthesis to inhibit the process, determining the decrease $\mathrm{NAA}^{23}$.

The asymmetry coefficient of NAA/Cho, NAA/Cr, Cho/Cr, and $\mathrm{NAA} / \mathrm{Cho}+\mathrm{Cr}$ between the hemispheres in neocortical extratemporal epilepsies may be explained by a metabolic abnormality characterized by the reduction of NAA in dysfunctional side, secondary to an augmentation of energy consumption due to a high metabolic activity necessary to generate abnormal electrical activity in epileptogenic zone. This change of metabolic activity promoted an increase in creatine synthesis, determining the reduction of $\mathrm{NAA} / \mathrm{Cr}$ ratio $^{24}$.

One can still admit that epilepsy, at cell level, consists of abnormal functioning derived by intercellular hyperexcitability associated with hypocellularity. This implies on admitting that brain tissue of epileptic patient presents cellular reduction expressed by the diminution of NAA, metabolic increase identified by creatine augmentation, and a great cellular turnover characterized by the choline increasing ${ }^{15}$.

The importance of this knowledge is to aid in the localization of epileptogenic zone on the orientation of surgical treatment. Therefore, when there is concordance of lateralization between EEG and MRI, the diagnose of this zone may be performed without another method, restricting MRS use to help anatomical localization in cases of discordance or doubt ${ }^{25}$. These affirmatives have been confirmed in this research by the lateralization concordance ratios of asymmetry coefficients equal to $100 \%$ for NAA/Cho and NAA/Cho+Cr and $33.3 \%$ for NAA/Cr, for patients with a concordant side of abnormalities in MRI and EEG.

Within clinical practice, when the results of MRI and EEG are inconclusive about the identification of epileptogenic zone, it requires the use of invasive methods such as profound electrodes or subdural grid and stripes - procedures of high cost. In such cases, the association of MRS may help surgical planning ${ }^{26}$.

The MRS with simultaneous multivoxel acquisition and long ET of 135 ms showed efficacy on lateralization of epileptogenic zone compared to MRI, which is a high sensibility and specificity method for patients with localized brain structural lesion, because the structural lesion is within the epileptogenic area, in most cases, independent of EEG lateralization. This may constitute one more resource to improve the confidence on localization and lateralization of brain area to be resected ${ }^{27}$.

The lateralization of epileptogenic zone compared with the lateralization of epileptogenic discharges, localized and lateralized by EEG, is less effective, because routine EEG is a method less sensible and specific to the determination of epileptogenic zone for neocortical extratemporal epilepsies ${ }^{21}$.

In this research, there was a great reduction in lateralization concordance ratios identified by NAA/Cho, NAA/Cr, and NAA/Cho+Cr asymmetry coefficients, when comparing lateralization and localization performed exclusively by routine EEG, independent of MRI findings, with altered EEG and normal MRI (78.6 to $33.3 \%, 31.6$ to $33.3 \%$, and 57.2 to $40 \%$, respectively). These differences suggested that the zones of interictal discharges may not coincide with epileptogenic zones ${ }^{15}$.

Additionally, when comparing patients with lateralization and localization performed exclusively by MRI abnormality, independent of EEG findings, with those with abnormal MRI and normal EEG, we identified the reduction of concordance ratios of NAA/Cho asymmetry coefficients (93.3 to 75\%), while for NAA/Cr and NAA/Cho+Cr asymmetry coefficients there was significant increase (57.9 to $100 \%$ and 93.3 to $100 \%$, respectively).

We must exercise caution to the interpretation of our findings, related to EEG sensibility and specificity, which can 
be a limitation of this research. Although the ictal EEG is admitted as gold standard for the localization and lateralization of epileptogenic zone, in some cases its accuracy does not provide the best conditions for guiding epileptic surgery. This research, as others in literature ${ }^{10,15,18,24,25}$, point out MRS as another option to contribute for localization and lateralization of epileptogenic zone in these cases.

Resuming, in this research, on one hand, we identified a low concordance between focal interictal EEG findings and MRS for the lateralization of epileptogenic zone. On the other hand, there was high coincidence of lateralization when we compared a localized lesion MRI with MRS, identified by the difference of NAA/Cho+Cr asymmetry coefficients between brain hemispheres.
According to these findings, we admitted that the asymmetry coefficients of brain metabolic ratios, which differ significantly between abnormal and normal hemispheres, demonstrate the interrelations between distinct metabolic pathways altered in epilepsies.

We concluded that MRS with simultaneous multivoxel and long ET $135 \mathrm{~ms}$ can be a complementary method for lateralization of epileptogenic zones in neocortical extratemporal epilepsies with structural lesion identified by MRI. It represents a great perspective of equal success on the lateralization of epileptogenic zones in the absence of MRI findings, but researches will be required for comparing MRS to invasive video EEG and stereo EEG (deep electrodes).

\section{References}

1. Leach JP, Stephen LJ, Salveta C, Brodie MJ. Which electroencephalography (EEG) for epilepsy? The relative usefulness of different EEG protocols in patients with possible epilepsy. J Neurol Neurosurg Psychiatry 2006;77:1040-1042.

2. Nóvak EM, Terabe F, Nasimoto AL, et al. Correlação entre hipótese diagnóstica e laudo de tomografia axial computadorizada craniana. Arq Neuropsiquiatr 2001;59:761-767.

3. Wright NB. Imaging in epilepsy: a paediatric perspective. Br J Radiol 2001;74:575-589.

4. Bonilha L, Montenegro MA, Cendes F, Li LM. The role of neuroimaging in the investigation of patients with single seizures, febrile seizures, or refractory partial seizures. Med Sci Monit 2004;10: RA40-RA46.

5. Connor SEJ, Jarosz JM. Magnetic resonance imaging of patients with epilepsy. Clin Radiol 2001;56:787-801.

6. Duncan JS, Sander JW, Sisodiya SM, Walker MC. Adult epilepsy. Lancet 2006;367:1087-1100.

7. Concha L, Gross W, Wheatley BM, Beaulieu C. Diffusion tensor imaging of time-dependent axonal and myelin degradation after corpus callosotomy in epilepsy patients. Neurolmage 2006;32:1090-1099.

8. Lee SK, Mori S, Kim DJ, et al. Diffusion tensor MRI and fiber tractography of cerebellar atrophy in phenytoin users. Epilepsia 2003;44:1536-1540.

9. Isik U, Dincer A, Özek MM. Surgical treatment of polymicrogyria with advanced radiologic and neurophysiologic techniques. Childs Nerv Syst 2007;23:443-448.

10. Danielsen ER, Ross B. Magnetic resonance spectroscopy diagnosis of surgical diseases. USA: Marcel Dekker, 1999:327.

11. Ross BD. A biochemistry primer for neuroradiologists. In: Advanced imaging symposium: preparing the neuroradiologist for the new millennium. Annual Meeting of the American Society of Neuroradiology, Atlanta 2000:13-27.

12. Henry RG, Vigneron DB, Fischbein NJ, et al. Comparison of relative cerebral blood volume and proton spectroscopy in patients with treated gliomas. Am J Neuroradiol 2000;21:357-366.

13. Bonavita S, Di Salle F, Tedeschi G. Proton MRS in neurological disorders. Eur J Radiol 1999;30:125-131.
14. Moffett JR, Ross B, Arun P, Madhavarao CN, Namboodiri AMA. $\mathrm{N}$-Acetylaspartate in the CNS: from neurodiagnostics to neurobiology. Prog Neurobiol 2007;81:89-131.

15. Krsek P, Hajik M, Dezortova M, et al. H MR spectroscopic imaging in patients with MRI-negative extratemporal epilepsy: correlation with ictal onset zone and histopathology. Eur Radiol 2007;8:2126-2135.

16. Palmini A. The concept of the epileptogenic zone: a modern look at Penfield and Jasper's views on the role of interictal spikes. Epileptic Disord 2006;8(Suppl 2):S10-S15.

17. Stanley JA, Cendes F, Dubeau F, Andermann F, Arnold DL. Proton magnetic resonance spectroscopic imaging in patients with extratemporal epilepsy. Epilepsia 1998;39:267-273.

18. Leite RAA, Otaduy MCG, Silva GEG, Ferreira MLB, Aragão MFV. Diagnostic methods for extra-temporal neocortical focal epilepsies. Arq Neuropsiquiatr 2010;68:119-126.

19. Blume W. Diagnosis and management of epilepsy. CMAJ 2003;168: 441-448.

20. Janszky J. Diagnosis of epilepsy. Ideggyogy Sz 2004;57:157-163.

21. Verma A, Radtke R. EEG of partial seizures. J Clin Neurophysiol 2006;23:333-339.

22. Briellmann RS, Pell GS, Wellard RM, et al. MR imaging of epilepsy: state of the art at 1.5 T and potential of 3 T. Epileptic Dis 2003;5:3-20.

23. Simister RJ, Mc Lean MA, Barker GJ, Duncan JS. A proton magnetic resonance spectroscopy study of metabolites in the occipital lobes in epilepsy. Epilepsia 2003;44:550-558.

24. Lundbom N, Gaily E, Vuori K, et al. Proton spectroscopic imaging shows abnormalities in glial and neuronal cell pools in frontal lobe epilepsy. Epilepsia 2001;42:1507-1514.

25. Willmann O, Wennberg R, May T, Woermann FG, Pohlmann-Eden B. The hole of ${ }^{1} \mathrm{H}$ magnetic resonance spectroscopy in pre-operative evaluation for epilepsy surgery. A meta-analysis. Epilepsy Res 2006;71:149-158.

26. Zumsteg D, Wieser HG. Presurgical evaluation: Current role of invasive EEG. Epilepsia 2000;41(Suppl 3):S55-S60.

27. Centeno R, Yacubian EM, Sakamoto AC, Ferraz AFP, Carrete Jr. $H$, Cavalheiro S. Pre-surgical evaluation and surgical treatment in children with extratemporal epilepsy. Childs Nerv Syst 2006; 22:945-959. 